\title{
Study on rainfall infiltration in high groundwater channels
}

\author{
Hui Chen ${ }^{1}$, Xiaodong Wang ${ }^{2}$, Xiaohui Wang ${ }^{3, *}$, and Xingpeng Song ${ }^{4}$ \\ ${ }^{1}$ State Key Laboratory of Simulation and Regulation of Water Cycle in River Basin, China Institute of Water Resources and Hydropower \\ Research, 20 West Chegongzhuang Rd.,Haidian District, Beijing 100048, China \\ ${ }^{2}$ Shandong Water Transfer Project Operation and Maintenance Center, Jinan 250100, China \\ ${ }^{3}$ Beijing Water Science and Technology Institute, Beijing 100048, China \\ ${ }^{4}$ Beijing Jingmi Canal Management Department, Beijing 101400, China
}

\begin{abstract}
In order to solve the adverse effect that the lining of high groundwater level channels is prone to damage when subjected to heavy rainfall, the response law of internal structural state of high groundwater level channels under different rainfall conditions was studied. Based on the non-seepage seepage theory, the seepage pressure (total water head) in the tunnel under four different rainfall types is analyzed and studied. The results show that the most unfavorable rainfall types for the lining structure safety are the frontal rainfall and uniform type rainfall. Therefore we should pay more attention to the front type and uniform type rainfall from the perspective of seepage. The research results can provide reference for slope and seepage control design of high groundwater level channels.
\end{abstract}

\section{Introduction}

In the layout and structure design of large flow and long distance water supply or irrigation channel, it is often encountered that the channel passes through the area of high groundwater level due to the influence of topographic and geological conditions. High groundwater may affect the stability of canal slope and lining structure, and affect the safety of canal operation. Rainfall is one of the important factors affecting the safety of slope and lining structure of high groundwater level channel. A large number of researchers have done in-depth studies on the seepage characteristics and stability changes of slope caused by rainfall. For example, Shi Zhenming et al. [1] proposed the stability analysis method of multi-layer unsaturated soil slope considering rainfall infiltration. Jiang Zhongming et al. [2] used FLAC3D software to propose three-dimensional unsaturated rainfall infiltration analysis of slope. Zhang Kefeng et al. [3] used Geostudio software to simulate the seepage stability law of a slope in the Three Gorges Reservoir area under the condition of sudden drop of reservoir water level and combined rainfall. Zeng Ling et al. [4] proposed a method for stability analysis of embankment slope based on saturated-unsaturated seepage and unsaturated shear strength theory. Li Bin et al. [5] calculated and analyzed the seepage state of the high slope of the south bank channel of the first phase of the middle route of the South-to-North Water Transfer Project through the Yellow River by using the threedimensional finite element simulation technology of steady and unsteady seepage.

However, there are few studies on rainfall infiltration in high groundwater channels. At present, due to the lack of corresponding drainage system, some high groundwater channels will produce large uplift pressure under the condition of heavy rainfall and cause damage to the lining structure of the channels [6].For example, the groundwater level near a section of the main canal of the middle route of the South-to-North Water Diversion Project is high. The rise of groundwater level caused by river leakage seriously affects the stability of the canal lining structure [7].

It is an important content in the design of canal to eliminate the adverse effect of groundwater on the lining plate by taking engineering measures. Channel response law of lining structure is calculated under different rainfall types (forward and center, after back, on average) to achieve a scientific study on the high groundwater on the influence law of canal lining and structural condition. The different change laws of pore pressure, safety coefficient changing with the rainfall process are obtained. The results can be used as the reference of optimal design of high groundwater canal slope and management.

\section{Unsaturated seepage theory}

The governing equation for unsaturated seepage calculation is as follows:

$$
\frac{\partial}{\partial x}\left(k_{x} \frac{\partial H}{\partial x}\right)+\frac{\partial}{\partial y}\left(k_{y} \frac{\partial H}{\partial y}\right)+Q=m_{2}^{w} \gamma_{w} \frac{\partial H}{\partial t}
$$

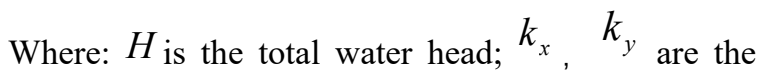
permeability coefficients of the direction; $Q$ is the

\footnotetext{
$\overline{{ }^{*} \text { Corresponding author: } 124647131 @ q q . c o m}$
} 
applied boundary flow; $\gamma_{w}$ is the weight of water; $\mathrm{t}$ is the time. $m_{2}^{w}$ is the slope of soil-water characteristic curve.

Fredlund\&Xing model is adopted for soil-water characteristic curve [8], and the corresponding equation is as follows:

$$
\theta_{w}=\theta_{s}\left[\ln \left(e+\left(\frac{\phi}{a}\right)^{n}\right)\right]^{-m}
$$

Where, $a, n, m$ are the fitting parameters, where $a$ is the air intake value, which mainly depends on the pore size; $n$ is the soil property parameter of the soil outflow rate function when the matric suction exceeds the soil intake value; $m$ is the soil property parameter of residual water content function, which is related to the global symmetry of characteristic curve. ${ }^{e}$ is the natural logarithm; $\phi$ is matric suction; $\theta_{w}$ is volume water content; $\theta_{s}$ is saturated volume moisture content.

The permeability coefficient curve is expressed as follows [9] :

$$
k_{\mathrm{w}}=k_{\mathrm{s}} \Theta^{\mathrm{p}}
$$

Where $k_{\mathrm{w}}$ is the permeability coefficient of unsaturated soil; $k_{\mathrm{s}}$ is the saturation permeability coefficient; $\Theta=\left(\theta_{\mathrm{W}} / \theta_{\mathrm{S}}\right)$ is the ratio of volumetric water content to saturated volume water content; $\mathrm{P}$ is the fitting parameter in the permeability coefficient curve.

\section{Engineering examples}

\subsection{Project overview}

After the operation of a water supply channel for more than 20 years, the groundwater level along the channel has changed in different degrees. For the channel segment where the groundwater level has risen, due to the lack of corresponding drainage system, a large uplift pressure has been generated, which causes the damage of the canal lining structure. Therefore, drainage measures are taken for high groundwater channels, and the scheme of collecting water from hidden pipes and discharging water from reverse drainage devices are adopted at the slope foot of the channels. When the local lower water level is higher than the channel water level, the reverse valve is opened to discharge the groundwater into the water transmission channel; Otherwise the valve closes. The design drawing of the typical section of the channel is shown in Figure 1(left half of the channel). In the normal operation process, the underground water level of this section of channel is about $2.60 \mathrm{~m}$. The water level in the channel is between $2.60-3.0 \mathrm{~m}$.

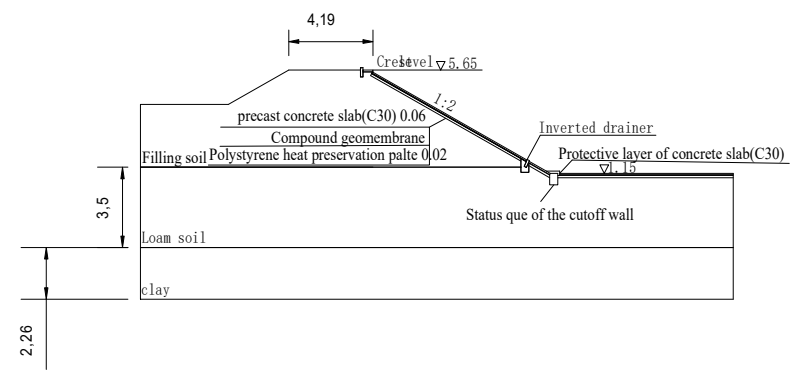

Fig. 1. Design drawing of typical section of channel

\subsection{Calculation mode}

\subsubsection{Calculation model and boundary condition setting}

The calculation model is shown in Figure 2.The ground surface is set as the rainfall flow boundary. The whole section of the channel is impermeable and considered impermeable. To reflect the most adverse conditions, the check valve has a fixed head boundary of $2.6 \mathrm{~m}$ (channel low water level) and an initial groundwater level marked by a blue line (water level $2.6 \mathrm{~m}$ ).

The grid size is set as $0.1 \mathrm{~m}$, the number of grids is 21616 , and the number of nodes is 21909 .

The following three typical representative nodes of the lining structure (marked positions in the figure) were selected for statistical analysis of the results.

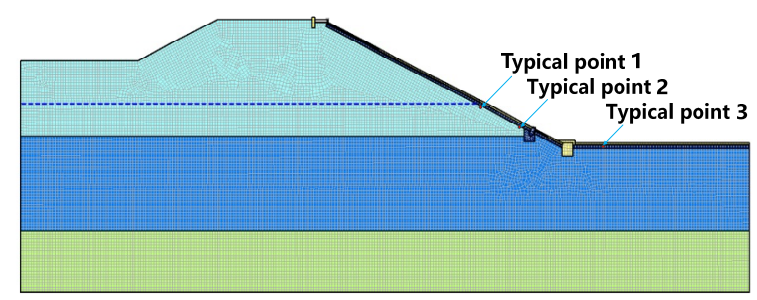

Fig. 2. Calculation model diagram

\subsubsection{Relevant parameters of the model}

The soil-water characteristic curve and the corresponding permeability coefficient curve in the process of seepage analysis are shown in Figure 3.

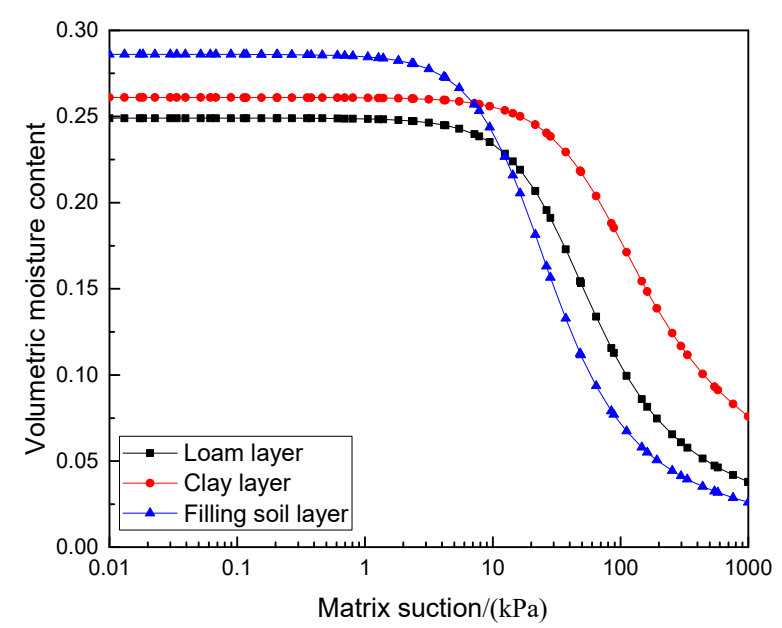

(a) Soil-water characteristic curve 


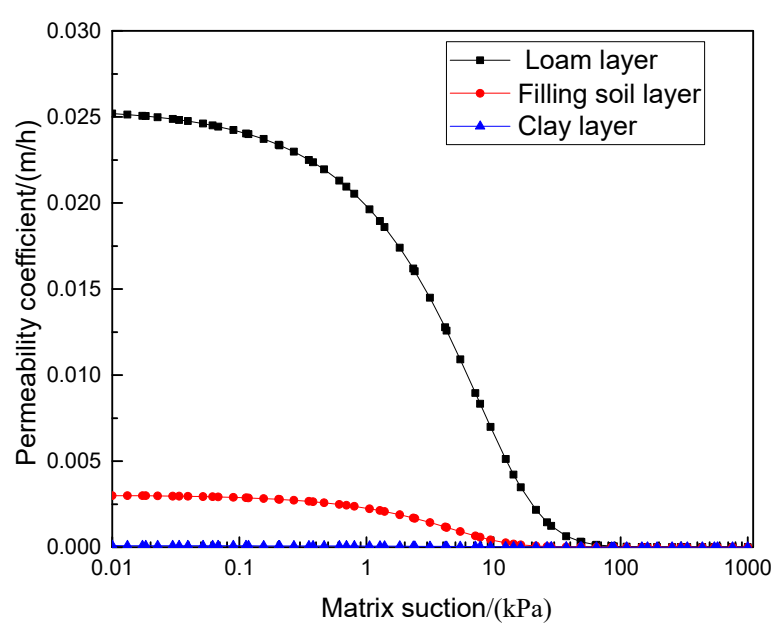

(b) Permeability curve

Fig. 3 Soil-water characteristic curve and permeability coefficient curve

\subsubsection{Rainfall process}

The rainfall intensity refers to the strongest rainfall in 50 years in the area covered by this section. Different types of rainfall were used, including forward type, back type, center type and average type. The total rainfall was $286 \mathrm{~mm}$, and the rainfall lasted for 33 hours. Rainfall processes of different rainfall types are shown in Fig. 4.

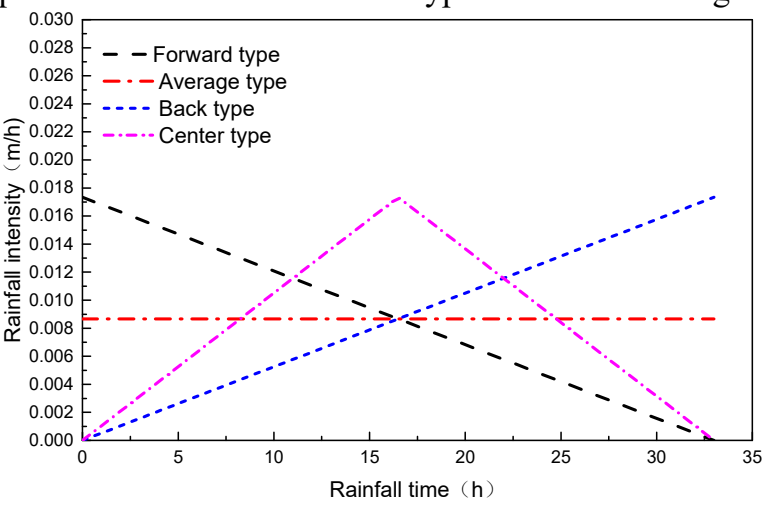

Fig. 4 Different rainfall process

\subsection{Analysis of calculation results}

The anti-floating stability coefficient of lining plate can be obtained by the following equation [10] :

$$
K_{\mathrm{f}}=\left(\gamma_{c}^{\prime} \cdot h_{c}\right) /\left(\gamma_{w} \cdot \Delta h\right)
$$

Where, $\gamma_{c}^{\prime}$ is the floating bulk density of lining slab, $\mathrm{kN} / \mathrm{m} 3 ; \gamma_{w}$ is water bulk density, $\mathrm{kN} / \mathrm{m} 3 ; h_{c}$ is the thickness of lining plate, $\mathrm{m} ; \Delta h$ is the difference between the bottom water head of lining plate and the channel water level, $\mathrm{m}$.

When the lining plate is in water, when $K_{\mathrm{f}}=1.0 h_{c}=0.06 \mathrm{~m}$ and the floating bulk density of the lining plate is $15 \mathrm{kN} / \mathrm{m} 3$, the obtained $\Delta h=0.09 m$.Therefore, when $\Delta h \geq 0.09 m$, the safety of the lining plate can be ensured.
Since the water level in the channel is $2.6 \mathrm{~m}$, that is, the total water head at the bottom of the lining plate cannot exceed $2.69 \mathrm{~m}$, otherwise the lining plate will be uplifted and damaged under the action of the pressure difference between upper and lower.

The end time of rainfall was selected to conduct seepage pressure analysis inside the channel, as shown in Fig. 5.According to the cloud image results, under various rain conditions, the maximum total water head range of the lining structure under the saturation line (blue dotted line) is between $2.7 \mathrm{~m}$ and $2.8 \mathrm{~m}$, which exceeds the critical water head of $2.69 \mathrm{~m}$. Therefore, the lining plate will be damaged under the action of rainfall.

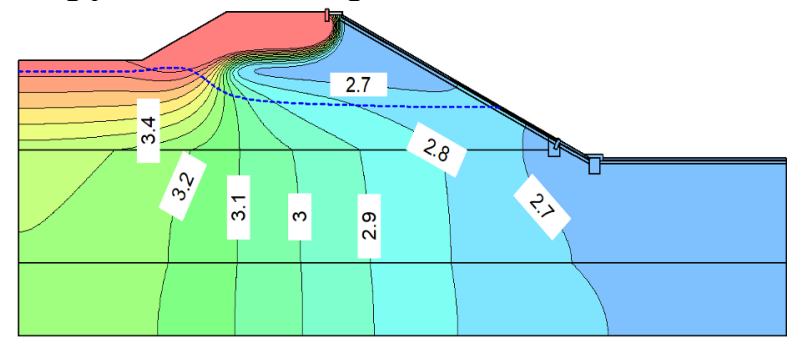

(a) Forward type

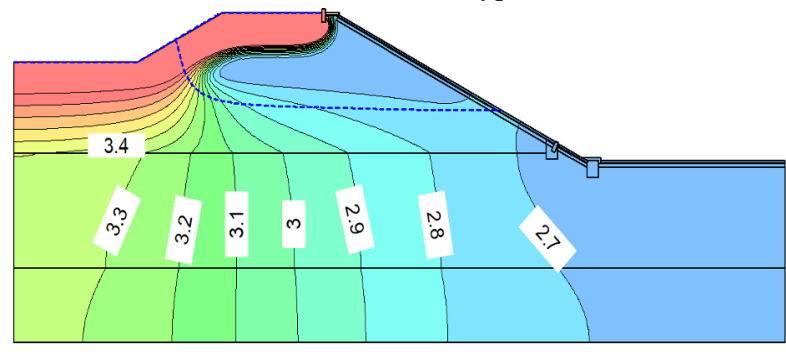

(b) Back type,

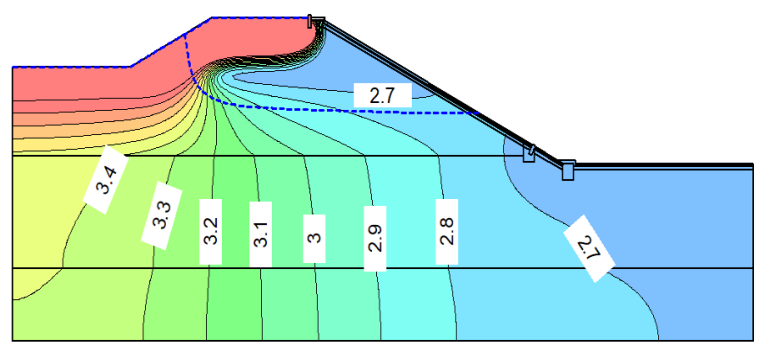

(c) Average type

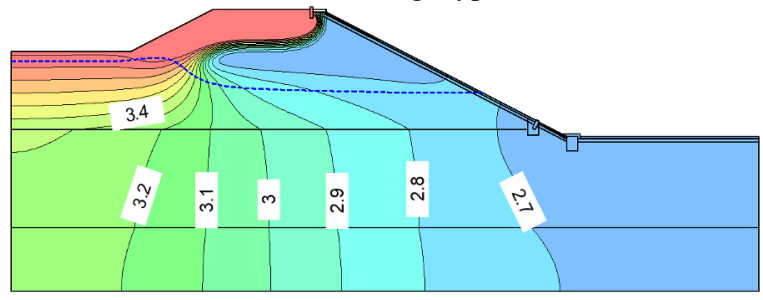

(d) Center type

Fig. 5 Percolation isopotential diagram (total head)

In order to study the difference in the influence of each rain type on the lining structure, the variation rule of the representative nodes 1, 2 and 3 under the lining plate with the total water head during the rainfall process was analyzed, as shown in Fig. 6. It can be seen that the total water head of representative points at corresponding times in the first 31 hours of the rainfall 
process is the forward type $>$ average type >center type >back type. In the last two hours, the size pattern is average type $>$ forward type $>$ center forward type $>$ back type. Therefore, the calculation results show that the most unfavorable rainfall process for lining structure are frontal rainfall and uniform-type rainfall.

Meanwhile, in the process of rainfall, the total water head of several rainfall conditions representing node 1 exceeds $2.69 \mathrm{~m}$ at the later stage of rainfall, so the lining structure at the location of node 1 May be damaged. Node 2 May be damaged under the condition of uniform and front rainfall, while node 3 is relatively safe.

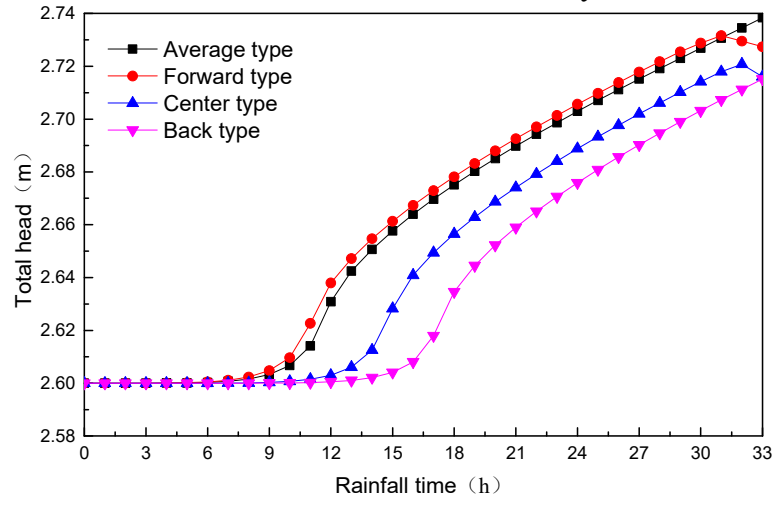

(a) Typical node 1

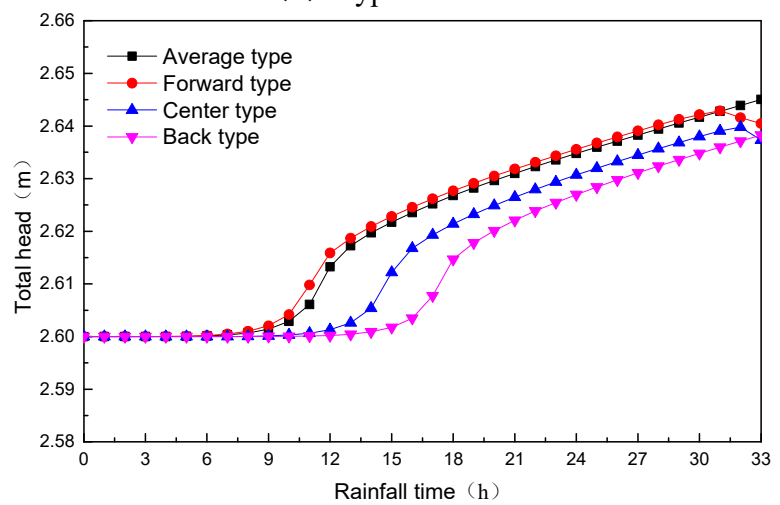

(b) Typical node 2

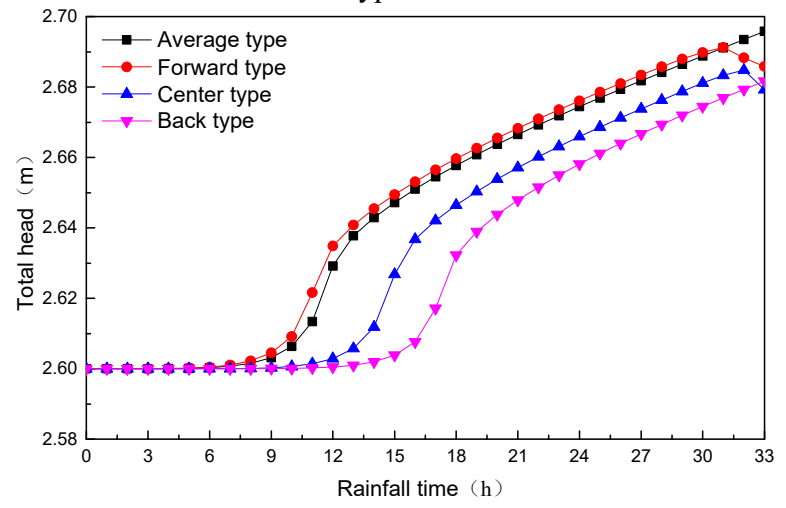

(c) Typical node 3

Fig. 6 Development of total water head of typical nodes under different rainfall patterns

From what has been discussed above, from the perspective of the internal seepage of high groundwater, it can be seen that the response law of seepage pressure in the channel caused by different rainfall types is different, among which the seepage pressure of forward type and average type rainfall increases faster and has stronger destructive force on the lining structure. Therefore, attention should be paid to the two types of rainfall in the design calculation. At the same time, the seepage response of different position of lining structure is also different, which should be fully analyzed in the design.

\section{Conclusion}

In this paper, the response law of internal structural state of high groundwater level channels under different types of heavy rainfall was deeply analyzed.

The seepage analysis shows that the response law of seepage pressure is different with different rainfall types, and the seepage pressure increases faster with forward type and average type rainfall, and the damage to lining structure is stronger. The two types of rainfall should be paid more attention in the design calculation. At the same time, the seepage response of different position of lining structure is also different, which should be fully analyzed in the design.

\section{Acknowledgments}

Financial support provided by the National Key R\&D Program of China (no. 2018YFC0407103) is gratefully acknowledged.

\section{References}

1. Z.M. Shi, D.W. Shen, M. Peng, et al. Slope stability analysis by considering rainfall infiltration in multilayered unsaturated soils. Journal of Hydraulic Engineering, 47(08): 977-985(2016).

2. Z.M. Jiang, X.H.Xiong, L. Zeng. Unsaturated seepage analysis of slope under rainfall condition based on FLAC3D.Rock and Soil Mechanics, 35(03): 855-861(2014).

3. K.F. Zhang. Study on Seepage Stability of Slope under Combined Action of Water Level Change and Rainfall Based on Grey Correlation Degree Theory. International Journal Hydroelectric Energy, 7(12):99-102(2019).

4. L. Zeng, H.Y. Fu, Z.M. He, et al. Impact of rainfall on stability of granular soil embankment slope considering saturated-unsaturated seepage. Journal of Central South University(Science and Technology), 45(10) :3614-3620(2014).

5. B. Li, H.T. Song, Y. Luo. Seepage analysis of high slope of loess channel. Yellow River, 31(11): 124125+127(2009).

6. Z.S. Li, L.L. Wang, T.H. Zhao, et al. Study on calculation method of drainage decompression system for canal lining. Yellow River, 32(05): 8384+87(2010).

7. .X.G. Chen. Study on anti-floating stability of the main channel of the middle route of the South-to- 
North Water Transfer Project under the action of groundwater. China Water Transport, 14(12): 216218(2010).

8. D.G. FREDLUND, A. XING. Equations for the soil-water characteristic curve. Canadian Geotechnical Journal, 31(4): 521-532(1994).

9. E.C. LEONG, H. RAHARDJO. Permeability functions for unsaturated soils. Journal of Geotechnical and Geoenvironmental Engineering, 123(12): 1118-1126(1997).

10. W.Huang, W.G. Xiao, X. Yao. Research on seepage control and drainage measures for high ground water canalsection in Middle Route Project of SNWaterDiversion. Yangtze River, 41(16):5558(2010). 